J. Dairy Sci. 99:3421-3433

http://dx.doi.org/10.3168/jds.2015-10119

(C) American Dairy Science Association ${ }^{\circledR}, 2016$.

\title{
Identifying the ideal profile of French yogurts for different clusters of consumers
}

\author{
M. Masson, ${ }^{*} \dagger^{1}$ A. Saint-Eve, $¥ \S$ J. Delarue, ${ }^{*} \dagger$ and D. Blumenthal ${ }^{*} \dagger$ \\ ${ }^{*}$ AgroParisTech, and \\ †INRA, UMR1145 Ingénierie Procédés Aliments, F-91300 Massy, France \\ $\ddagger$ AgroParisTech, and \\ §INRA, UMR782 Génie et microbiologie des procédés Alimentaires, F-78850, Thiverval-Grignon, France
}

\begin{abstract}
Identifying the sensory properties that affect consumer preferences for food products is an important feature of product development. Different methods, such as external preference mapping or partial least squares regression, are used to establish relationships between sensory data and consumer preferences and to identify sensory attributes that drive consumer preferences, by highlighting optimum products. Plain French yogurts were evaluated by a sensory profiling method performed by 12 trained judges. In parallel, 180 consumers were asked to score their overall liking and complete a cognitive restraint questionnaire. After hierarchical cluster analysis on the liking scores, preference mapping using a quadratic regression model was performed. Five clusters of consumers were identified as a function of different preference patterns. Contrary to our expectations, fat levels were not discriminating. For each cluster, the results of preference mapping enabled the identification of optimum products. A comparison of the 5 sensory profiles revealed numerous differences between key sensory attributes. For example, one consumer cluster had a strong preference for products perceived as very thick, grainy, but with a less flowing texture, less sticky, whey presence and color, in contrast to other clusters. In addition, each segment of consumers was characterized according to the results of the cognitive restraint questionnaire.
\end{abstract}

Key words: preference mapping, sensory profile, drivers of preference

\section{INTRODUCTION}

The market for dairy products has seen sustained growth and it continues to expand each year with the

Received July 15, 2015.

Accepted December 22, 2015 .

${ }^{1}$ Corresponding author: marine.masson@agroparistech.fr emergence of new fresh dairy products. In France, for example, the consumption of yogurts has reached 21 kg per capita per year (CNIEL, 2012) and many new products are introduced each year. Formulations (composition and process) vary between different products on the market and affect their structure and rheological and sensory properties, as has been highlighted by numerous studies and reviews (Sodini et al., 2004; Chandan and O'Rell, 2006). In the literature, properties of yogurts have been studied relative to consumer appreciation in target markets (Barnes et al., 1991; Harper et al., 1991; Pohjanheimo and Sandell, 2009). The main interest of these studies is to reduce the gap that may exist between product development and consumer expectations, and consequently to reduce the number of failed new products that may disappear each year from the market. As a result, improving the identification of drivers of liking appears to be a necessary part of the development of new yogurts that will account for these drivers.

Identifying the sensory properties that affect consumer preferences for food products can provide useful information for product development. The sensory properties of products are generally evaluated using descriptive methods, such as conventional profiling. In parallel, determining hedonic responses to products involves asking consumers to identify their preferences. To establish relationships between sensory data and consumer preferences, different multivariate statistical methods such as external preference mapping (Chang and Carroll, 1972) or partial least squares (PLS) regression (Wold et al., 1984) can be used. Optimized products can also be identified by highlighting sensory attributes that drive liking. In the literature, external preference mapping has been applied to various food products (Hough et al., 1992; Munoz and Chambers, 1993; Daillant-Spinnler et al., 1996; Arditti, 1997; Helgesen et al., 1997; Hough and Sánchez, 1998; Elmore et al., 1999; Guinard et al., 2001; Faber et al., 2003; Dooley et al., 2010; Bonany et al., 2014). In these studies, principal component analysis (PCA) was first performed 
Table 1. Composition and texture characteristics of the 8 yogurts studied

\begin{tabular}{llllll}
\hline Yogurt & Brand $^{1}$ & Starter & Texture & $\begin{array}{l}\text { Lipid content } \\
(\mathrm{g} / 100 \mathrm{~g})\end{array}$ & $\begin{array}{l}\text { Three-letter } \\
\text { code }\end{array}$ \\
\hline Product 1 & Danone & Standard & Set & $>0$ & Y-F-S \\
Product 2 & Danone & Standard & Set & 0 & Y-F-A \\
Product 3 & Danone & Standard & Stirred & $>0$ & Y-B-S \\
Product 4 & Danone & Standard & Stirred & 0 & Y-B-A \\
Product 5 & Danone & Bifidus & Set & $>0$ & B-F-S \\
Product 6 & Danone & Bifidus & Set & 0 & B-F-A \\
Product 7 & Danone & Bifidus & Stirred & $>0$ & B-B-S \\
Product 8 & Auchan & Bifidus & Stirred & 0 & B-B-A \\
\hline
\end{tabular}

${ }^{1}$ Danone, Paris, France; Auchan, Croix, France.

on sensory data. Liking scores were then regressed on the axes of the PCA for each consumer. Four types of regression model can be used; vector, circular, elliptic, or quadratic (Schlich, 1995). Individual models could thus be estimated. This approach made it possible to find an optimum area on the plane to define the sensory characteristics of optimum products.

When focusing on dairy products, the relationships between sensory data and consumer preferences have been investigated using different methods: (1) PLS regression; for example, on Greek yogurts (Desai et al., 2013); (2) a vector regression model; for example, on strained yogurt in the Lebanese market (Kaaki et al., 2012); and (3) a quadratic regression model; for example, on dulce de leche (Gaze et al., 2015). In this last study, the authors emphasized the existence of an ideal product that could be useful to optimize the sensory quality of products and thus increase the probability of their acceptance by consumers. As suggested by the authors, this could also ensure improved profits for manufacturers. But apart from these studies, an ideal profile has rarely been addressed because of the confidentiality of data, and, more importantly, certain methodological limitations such as having a sufficient number of test products to establish statistical models.

In this context, the objective of the present study was (1) to determine the drivers of liking of yogurts using external preference mapping with a quadratic model, and (2) to quantify the intensities of each sensory descriptor of ideal products in clusters of consumers. To achieve this, 8 products were studied. They were chosen to be as broadly representative as possible of the French market for plain yogurts. In parallel with a sensory profile performed by a trained panel, 180 consumers were asked to score their overall liking of the yogurts. Clusters of consumers were identified as a function of their hedonic scores of the products. Preference mapping with a quadratic regression model was performed on each cluster, and an optimum product was thus identified for each one. Finally, the different groups were characterized using a cognitive restraint questionnaire.

\section{MATERIALS AND METHODS}

\section{Products}

Eight commercial yogurts were studied. They were chosen to create a broad range that included set and stirred yogurts, with or without a health component (Bifidus content), and with differing fat contents (lowfat and semi-skim milk), according to a full factorial design with three 2-level factors.

The samples were coded using a 3-letter code (e.g., Y-B-S; Table 1). The first letter corresponded to the starter culture ( $\mathbf{Y}$ for standard yogurt or $\mathbf{B}$ for Bifidus); the second letter corresponded to the texture $-\mathbf{B}$ for "brassé" (stirred) or F for "ferme" (set). The last letter corresponded to the lipid content, with $\mathbf{S}$ for standard (>0 g per $100 \mathrm{~g}$ of product) and $\mathbf{A}$ for $0 \%$ (0 g per 100 $\mathrm{g}$ of product). All yogurts were tested midway through their shelf lives and were served just before tasting.

\section{Sensory Characterization}

A group of 12 panelists (25-60 yr old; 9 women and 3 men) were selected for their motivation and their ability to describe fresh dairy products. The evaluation was carried out in a standardized room containing separate booths. Ten sessions were completed, including training and evaluation. First, the 12 panelists generated a vocabulary of sensory attributes that covered the appearance, odor, texture, taste, aroma, and aftertaste of the yogurt samples. This was completed by a consensus phase, which enabled compilation of a list of 27 attributes with their definitions and protocols for evaluation (Table 2). Three sessions were then carried out to train the panel on the appearance and texture, odor, taste, aroma, and aftertaste attributes. Finally, panelists were trained in use of a 10-cm unstructured linear scale. 
Table 2. List of sensory attributes and their definitions

\begin{tabular}{|c|c|c|}
\hline Attribute & Definition & Scale anchors \\
\hline \multicolumn{3}{|l|}{ Visual } \\
\hline Amount of whey & Amount of whey on the surface of the yogurt & Absent/high \\
\hline Color & Color of yogurt & White/ivory \\
\hline Granularity on the surface area & $\begin{array}{l}\text { Quantity of particulates on the surface of the product (tilt the yogurt to prevent whey affecting } \\
\text { evaluation) }\end{array}$ & Not/many \\
\hline Brilliance & Visual aspect of the surface light reflections (tilt the yogurt to prevent whey affecting evaluation) & Absent/very \\
\hline Crisp with spoon & $\begin{array}{l}\text { Once having put the spoon in the yogurt, evaluation of the residual trace in the yogurt (the neater the } \\
\text { trace, the crisper the yogurt) }\end{array}$ & Not/very \\
\hline Sticking with spoon & Property of yogurt to stick to the spoon & Not/very \\
\hline Flowing texture & Property of yogurt to flow under the spoon & Not/very \\
\hline Granularity in the spoon & Quantity of particulates of the product in spoon (mixing the yogurt 3 times before evaluation) & Not/many \\
\hline \multicolumn{3}{|c|}{ 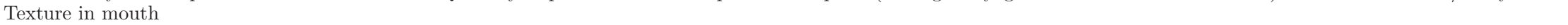 } \\
\hline Thickness & Strength used to compress food against the palate & Not/very \\
\hline Granularity in mouth & Quantity of particulates in mouth & No/many \\
\hline Powdery texture & Rough sensation by friction between tongue and palate & Not/very \\
\hline Sticking in mouth & Sticky feeling perceived between teeth and tongue, when manipulating the product in the mouth & Not/very \\
\hline \multicolumn{3}{|l|}{$\begin{array}{l}\text { Odor (yogurt mixed } 3 \text { times before } \\
\text { evaluation) }\end{array}$} \\
\hline Spicy odor & Spicy odor of the yogurt & Not/very intense \\
\hline Animal odor & Animal odor of the yogurt & Not/very intense \\
\hline Fermentation odor & Fermentation odor of the yogurt & Not/very intense \\
\hline Vanilla odor & Vanilla odor of the yogurt & Not/very intense \\
\hline \multicolumn{3}{|l|}{ Taste } \\
\hline Acid & Basic taste, perceived on the tongue, stimulated by acids & Not much/very \\
\hline Bitter & Basic taste, perceived on the tongue, stimulated by substances such as quinine or caffeine & Not/very \\
\hline Sweet & Basic taste, perceived on the tongue, stimulated by sugars & Not/very \\
\hline \multicolumn{3}{|c|}{ (1) 1} \\
\hline Milk flavor & Retronasal aroma perception to milk products & Not/very intense \\
\hline Butter flavor & Retronasal aroma perception to fresh butterfat & Not/very intense \\
\hline \multicolumn{3}{|c|}{ 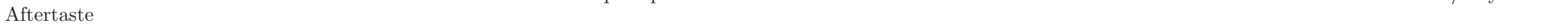 } \\
\hline Acid aftertaste & Intensity of acid after taste after swallowing & Not/very \\
\hline Bitter aftertaste & Intensity of bitter after taste after swallowing & Not/very \\
\hline Fermentation aftertaste & Intensity of bitter fermentation taste after swallowing & Not/very \\
\hline Mouth coating & Intensity of bitter aftertaste after swallowing & Not/very \\
\hline Astringent & The feeling factor on the tongue or other skin surfaces of the mouth described as puckering or drying & Not/very \\
\hline Fat aftertaste & Retronasal aroma perception to fresh butterfat or sweet cream after swallowing & Not/very \\
\hline
\end{tabular}


For the measurements, sample evaluations were made during 4 sessions (2 replicates). The yogurts were presented and tested monadically following a balanced presentation order, and were coded with 3-digit numbers. Each panelist scored all the attributes for each yogurt by using $10-\mathrm{cm}$ unstructured linear scales.

\section{Consumer Evaluation}

One hundred eighty consumers were recruited for the test in the Paris area (72 men and 108 women, aged between 18 and $80 \mathrm{yr}$ ). Their recruitment was based on the following criteria: they had to be consumers of plain yogurt (without added sugar) at least once a week, and be representative, in age and sex, of plain yogurt consumers in France. The assessment was performed in 2 sessions in a standardized room containing separate booths (4 yogurts were tested during the first session and 4 yogurts during the second). The products were presented using a 3 digit-code in a monadic way according to a balanced presentation order to prevent carryover effects. First, liking of the yogurt was assessed using a 9-point hedonic scale, and then consumers were asked about their subjective perceptions (data not shown). The subjects then completed a cognitive restraint questionnaire that combined a 3 -factor eating questionnaire (Stunkard and Messick, 1985) and a questionnaire regarding satiety in 6 parts: (1) lifestyle and nutritional habits, (2) appetite, (3) satiety, (4) purchase intent of yogurts with satiating effect, (5) expectation for this product, and (6) expected benefits of this product.

\section{Statistical Analysis}

Sensory Data Analysis. The statistical analysis of data was performed using XLSTAT 2015.1 software (Addinsoft, Paris, France), Matlab R2014.b (MathWorks, Natick, MA), and SAS software (version 9.4, SAS Institute Inc., Cary, NC). Two-way ANOVA with product, subject (fixed effects), and product $\times$ subject interaction was applied to the sensory data to determine the discriminating attributes and investigate the performance of the panel. When significant differences were revealed between products $(P<0.05)$, mean intensities were compared using the Newmans-Keuls multiple comparison test to form different groups of products. Two-way ANOVA with repetition and product effects and product $\times$ repetition interaction was then performed to determine the repeatability of the panel.

Consumer Preferences. Liking scores that differed between the yogurts were compared using ANOVA with
2 factors: subject and product. Hierarchical clustering analysis (HCA; Euclidean distance, Ward criteria) was then performed on normalized consumer-liking scores to identify clusters of consumers with similar preference patterns. Two-way ANOVA with group, product, and cluster $\times$ product effects was then performed to analyze differences in liking scores between yogurts and between clusters. Finally, for each cluster, an ANOVA with product, consumer, and order of presentation effect was performed to analyze differences in liking scores between the yogurts.

External Preference Mapping. Principal component analysis was performed on the sensory data. Each consumer's liking score was then regressed on the dimensions of the normalized PCA with an eigenvalue $>1$. As is usual in preference mapping with a quadratic model, the scores were normalized for each consumer. To define the optimums, the most complex model used was the full quadratic model (equation 1):

$$
\begin{aligned}
Y_{i}(k) & =a_{0, i}+b_{1, i}, x_{1, k}+b_{2, i} x_{2, k}+c_{1, i} x_{1, k}^{2}+c_{2, i} x_{2, k}^{2} \\
& +d_{i} x_{1, k} x_{2, k}+E_{i},
\end{aligned}
$$

where $Y_{i}(k)$ is the standardized score of $k$ product for consumer $i ; a_{0, i}$ is the intercept, $b_{1, i}$ and $b_{2, i}$ are the regression coefficients for the first 2 axes; $x_{1, k}$ and $x_{2, k}$ are factorial coordinates of the product; $c_{1, i}$ and $c_{2, i}$ are the quadratic terms; $d_{i}$ is the interaction term; and $E_{i}$ is a random variable with a normal distribution and the same variance.

For each consumer, the surface plot was discretized: $>0$ (a preference threshold corresponding to the mean of the scores of a particular consumer on normalized scores), the surface took a value of $1 ;<0$, the surface took a value of 0 (Danzart et al., 2004; Figure 1a). This discretization would enhance preference and rejection areas for each consumer. The modified individual surfaces were summed to aggregate the consumers and thus produce a final surface (Figure 1b). For any point on the sensory map, this surface would indicate the estimated number of consumers who would give the corresponding product a higher score than their average score for the products under evaluation (i.e., the number of consumers appreciating the corresponding product).

From the few statistical methods to validate the final model, before designing a new product and verifying that it is appreciated at the predicted level, we chose to compute correlation coefficients between the predicted and real values for each product. Thus, for each studied product, we calculated the number of consumers who actually appreciated this product and then compared 


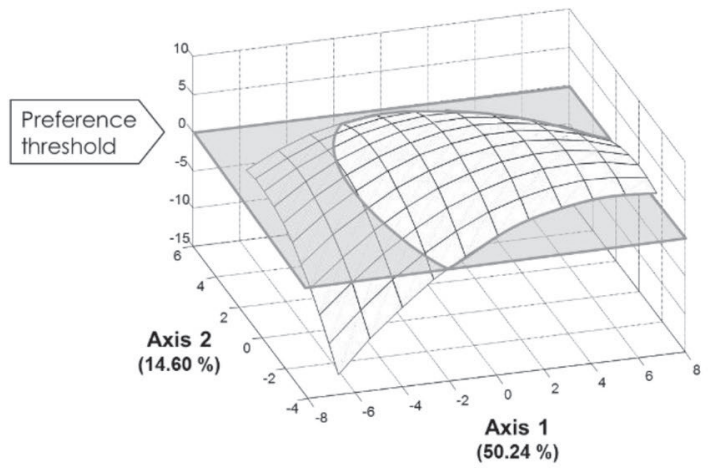

a

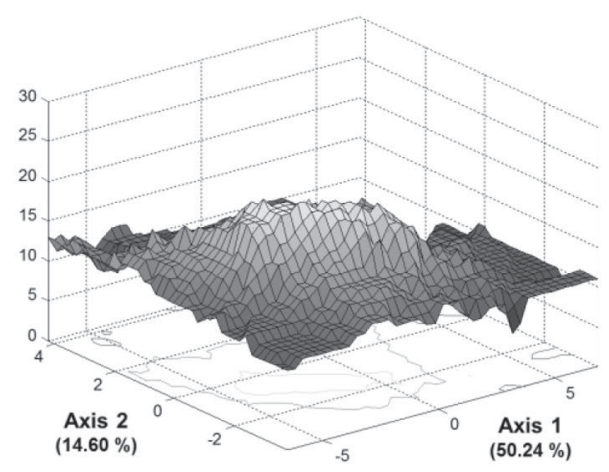

$\mathrm{b}$

Figure 1. (a) Discretization of the surface of one consumer; and (b) final surface for all consumers after discretization. Axes 1 and 2 correspond to plan of principal component analysis obtained with sensory data. For (a) the third axis corresponds to individual preference model and an example of discretization, and for (b) the third axis corresponds to the cumulative sum of models obtained after discretization for all consumers.

this number with the estimated number generated by the model.

To compare the numbers of consumers for each product, we computed the correlation coefficient (r) between real and estimated numbers (Equation 2). The closer the coefficient was to 1 , the better the model:

$$
r=\frac{\frac{1}{n} \sum_{i=1}^{n}\left(\hat{z}_{i}-\overline{\hat{z}}\right)\left(z_{i}-\bar{z}\right)}{s_{\hat{z}} s_{z}}
$$

where $z_{i}$ is the measured number of satisfied consumers for product $i, s_{z}$ is the corresponding standard deviation, $\hat{z}_{i}$ is the estimated number of satisfied consumers for product $i, s_{\hat{z}}$ is the corresponding standard deviation, and $n$ is the number of products.

If the model is considered satisfactory, we can estimate the sensory values of the optimum product; that is, the product with the highest number of satisfied consumers (centroid method; Blumenthal and Bouillot, 2010). Because we can construct a global final surface, we can also construct a global surface for each cluster of customers.

\section{RESULTS}

\section{Sensory Findings}

First, we determined the performance of the panelists and panel. To study the reliability of the panel with respect to 2 evaluations, a repetition effect was estimated. A product $\times$ repetition effect was observed for 2 of 27 attributes (amount of whey and acid aftertaste) and was taken into account when interpreting the re- sults. The homogeneity of the panel was determined by evaluating the interaction between the product and panelist for each attribute. Significant product $x$ subject interactions $(P<0.05)$ were observed for 5 attributes (granularity on the surface, brilliance, sticking to the spoon, flowing texture, granularity in the spoon). However, the good discriminating ability of the panel $(P<0.0001$ for the product effect) demonstrated that disagreements between panelists were mainly due to differences in the use of the scoring scales. The discriminatory power of the panel was then determined, with the product effect resulting from 2-way ANOVA. The results revealed no significant differences between the yogurts for 8 of 27 attributes (spicy odor, animal odor, fermentation odor, vanilla odor, bitter, bitter aftertaste, fermentation aftertaste, powdery texture; $P>$ $0.05)$, so they were not interpreted further. The yogurts were therefore perceived to be significantly different with respect to 19 of 27 attributes. Globally, satisfactory performance of the panelists, and hence the panel, was therefore observed.

The results of Newman-Keuls pair comparison tests are presented in Table 3 and showed that stirred and set products were mainly opposed regarding visual attributes (crisp with spoon, sticking with spoon, and granularity in the spoon), texture in mouth attributes (granularity in mouth), taste attributes (sweet), and aftertaste attributes (mouth coating). The Y-F-S yogurt was perceived as being the most acid, the most astringent, and having the most acid aftertaste intensity.

\section{Preferences}

Preference Analysis. Significant differences in liking scores between products and subjects were observed 
Table 3. Averaged perceived intensities (across subjects and replicates) of the 8 yogurts studied for each sensory attribute, together with their associated F-values ${ }^{1}$

\begin{tabular}{|c|c|c|c|c|c|c|c|c|c|c|c|c|}
\hline \multirow[b]{2}{*}{ Attribute } & \multirow[b]{2}{*}{$\mathrm{F}_{\text {model, }, 95,96}$} & \multirow[b]{2}{*}{$\mathrm{F}_{\text {product }, 7,96}$} & \multirow[b]{2}{*}{$\mathrm{F}_{\text {subject, } 11,96}$} & \multirow[b]{2}{*}{$\mathrm{F}_{\text {prod } \times \text { subj, } 77,96}$} & \multicolumn{8}{|c|}{ Yogurt } \\
\hline & & & & & Y-B-S & B-B-A & B-B-S & B-F-S & Y-B-A & Y-F-A & Y-F-S & B-F-A \\
\hline \multicolumn{13}{|l|}{ Visual } \\
\hline Amount of whey & 3.9 & 33.0 & 4.8 & 1.2 & $1.8^{\mathrm{d}}$ & $5.7^{\mathrm{b}}$ & $2.5^{\mathrm{d}}$ & $3.8^{\mathrm{c}}$ & $8.1^{\mathrm{a}}$ & $5.8^{\mathrm{b}}$ & $1.2^{\mathrm{d}}$ & $7^{\mathrm{a}, \mathrm{b}}$ \\
\hline Color & 2.6 & 17.5 & 4.0 & 1.0 & $6.6^{\mathrm{a}, \mathrm{b}}$ & $7.4^{\mathrm{a}}$ & $5.5^{\mathrm{b}, \mathrm{c}}$ & $2.6^{\mathrm{e}}$ & $7.2^{\mathrm{a}}$ & $4.5^{\mathrm{c}, \mathrm{d}}$ & $3.2^{\mathrm{d}, \mathrm{e}}$ & $4.2^{\mathrm{c}, \mathrm{d}}$ \\
\hline Granularity on the surface area & 4.9 & 18.9 & 14.8 & 2.2 & $0.6^{\mathrm{c}}$ & $1^{\mathrm{c}}$ & $0.8^{\mathrm{c}}$ & $2.7^{\mathrm{b}}$ & $0.7^{\mathrm{c}}$ & $2.9^{\mathrm{b}}$ & $1.7^{\mathrm{c}}$ & $4^{\mathrm{a}}$ \\
\hline Brilliance & 4.3 & 6.3 & 17.8 & 2.1 & $6.9^{\mathrm{a}}$ & $7.5^{\mathrm{a}}$ & $7.3^{\mathrm{a}}$ & $5.4^{\mathrm{b}}$ & $7.4^{\mathrm{a}}$ & $6.5^{\mathrm{a}, \mathrm{b}}$ & $5.7^{\mathrm{b}}$ & $6.3^{\mathrm{a}, \mathrm{b}}$ \\
\hline Crisp with spoon & 13.2 & 161.7 & 3.4 & 1.2 & $0.7^{\mathrm{c}}$ & $1^{\mathrm{c}}$ & $0.4^{\mathrm{c}}$ & $7.9^{\mathrm{a}, \mathrm{b}}$ & $0.3^{\mathrm{c}}$ & $7.3^{\mathrm{b}}$ & $8.5^{\mathrm{a}}$ & $7.5^{\mathrm{a}, \mathrm{b}}$ \\
\hline Sticking with spoon & 5.6 & 47.3 & 4.2 & 2.0 & $6.4^{\mathrm{a}}$ & $5.6^{\mathrm{a}}$ & $5.5^{\mathrm{a}}$ & $1.7^{\mathrm{b}}$ & $6^{\mathrm{a}}$ & $0.6^{\mathrm{b}}$ & $1.6^{\mathrm{b}}$ & $1^{\mathrm{b}}$ \\
\hline Flowing texture & 5.8 & 62.0 & 4.9 & 0.8 & $5.7^{\mathrm{b}}$ & $7.1^{\mathrm{a}}$ & $5.4^{\mathrm{b}}$ & $0.4^{\mathrm{c}}$ & $6.5^{\mathrm{a}, \mathrm{b}}$ & $0.6^{\mathrm{c}}$ & $0.4^{\mathrm{c}}$ & $0.4^{\mathrm{c}}$ \\
\hline Granularity in the spoon & 16.0 & 187.9 & 5.1 & 1.9 & $0.6^{\mathrm{b}}$ & $0.5^{\mathrm{b}}$ & $0.6^{\mathrm{b}}$ & $7.6^{\mathrm{a}}$ & $0.5^{\mathrm{b}}$ & $7^{\mathrm{a}}$ & $7.9^{\mathrm{a}}$ & $7.6^{\mathrm{a}}$ \\
\hline \multicolumn{13}{|l|}{ Texture in mouth } \\
\hline Thickness & 2.2 & 7.9 & 4.8 & 1.4 & $2.5^{\mathrm{b}, \mathrm{c}}$ & $4.3^{\mathrm{a}}$ & $1.6^{\mathrm{c}}$ & $4.9^{\mathrm{a}}$ & $1.9^{\mathrm{c}}$ & $4^{\mathrm{a}, \mathrm{b}}$ & $3.4^{\mathrm{a}, \mathrm{b}}$ & $3.7^{\mathrm{a}, \mathrm{b}}$ \\
\hline Granularity in mouth & 7.5 & 71.7 & 8.3 & 1.6 & $0.5^{\mathrm{d}}$ & $0.5^{\mathrm{d}}$ & $0.4^{\mathrm{d}}$ & $4.5^{\mathrm{c}}$ & $0.6^{\mathrm{d}}$ & $6^{\mathrm{a}, \mathrm{b}}$ & $5.4^{\mathrm{b}, \mathrm{c}}$ & $6.7^{\mathrm{a}}$ \\
\hline Powdery texture & 1.6 & 1.4 & 5.6 & 1.0 & $2.8^{\mathrm{a}}$ & $4.5^{\mathrm{a}}$ & $2.6^{\mathrm{a}}$ & $3.3^{\mathrm{a}}$ & $3.4^{\mathrm{a}}$ & $3.3^{\mathrm{a}}$ & $3.7^{\mathrm{a}}$ & $2.8^{\mathrm{a}}$ \\
\hline Sticking in mouth & 2.2 & 5.9 & 7.6 & 1.1 & $3^{\mathrm{b}}$ & $4.6^{\mathrm{a}}$ & $2.1^{\mathrm{b}}$ & $2.8^{\mathrm{b}}$ & $2.1^{\mathrm{b}}$ & $2^{\mathrm{b}}$ & $1.7^{\mathrm{b}}$ & $1.8^{\mathrm{b}}$ \\
\hline \multicolumn{13}{|l|}{ Odor } \\
\hline Spicy odor & 1.5 & 1.3 & 6.2 & 0.9 & $3.4^{\mathrm{a}}$ & $3.5^{\mathrm{a}}$ & $4^{\mathrm{a}}$ & $3.7^{\mathrm{a}}$ & $3.9^{\mathrm{a}}$ & $4^{\mathrm{a}}$ & $5.3^{\mathrm{a}}$ & $4.2^{\mathrm{a}}$ \\
\hline Animal odor & 1.7 & 0.4 & 8.2 & 0.8 & $4.2^{\mathrm{a}}$ & $3.6^{\mathrm{a}}$ & $4.1^{\mathrm{a}}$ & $3.9^{\mathrm{a}}$ & $4.4^{\mathrm{a}}$ & $4.5^{\mathrm{a}}$ & $4.3^{\mathrm{a}}$ & $3.8^{\mathrm{a}}$ \\
\hline Fermentation odor & 1.7 & 0.8 & 6.8 & 1.0 & $4.8^{\mathrm{a}}$ & $4.3^{\mathrm{a}}$ & $4.8^{\mathrm{a}}$ & $4.4^{\mathrm{a}}$ & $4.5^{\mathrm{a}}$ & $5.5^{\mathrm{a}}$ & $5.3^{\mathrm{a}}$ & $4.9^{\mathrm{a}}$ \\
\hline Vanilla odor & 3.6 & 2.2 & 20.3 & 1.4 & $1.3^{\mathrm{a}}$ & $2.1^{\mathrm{a}}$ & $2^{\mathrm{a}}$ & $1.1^{\mathrm{a}}$ & $1^{\mathrm{a}}$ & $1.3^{\mathrm{a}}$ & $0.9^{\mathrm{a}}$ & $1.4^{\mathrm{a}}$ \\
\hline \multicolumn{13}{|l|}{ Taste } \\
\hline Acid & 1.6 & 6.9 & 4.5 & 0.7 & $4.1^{\mathrm{b}}$ & $4.5^{\mathrm{b}}$ & $4.7^{\mathrm{b}}$ & $5.9^{\mathrm{b}}$ & $5.4^{\mathrm{b}}$ & $4.5^{\mathrm{b}}$ & $8.1^{\mathrm{a}}$ & $4.4^{\mathrm{b}}$ \\
\hline Bitter & 1.5 & 1 & 3.5 & 1.2 & $4.2^{\mathrm{a}}$ & $3.7^{\mathrm{a}}$ & $3.9^{\mathrm{a}}$ & $4.4^{\mathrm{a}}$ & $5.1^{\mathrm{a}}$ & $3.7^{\mathrm{a}}$ & $3.7^{\mathrm{a}}$ & $4.6^{\mathrm{a}}$ \\
\hline Sweet & 2.1 & 5.0 & 9.3 & 0.8 & $2.7^{\mathrm{a}}$ & $2.9^{\mathrm{a}}$ & $2.5^{\mathrm{a}}$ & $1.2^{\mathrm{b}}$ & $2.6^{\mathrm{a}}$ & $1.4^{\mathrm{b}}$ & $0.9^{\mathrm{b}}$ & $1.2^{\mathrm{b}}$ \\
\hline \multicolumn{13}{|l|}{ Aroma } \\
\hline Milk flavor & 1.6 & 4.5 & 5.7 & 0.8 & $6.5^{\mathrm{a}}$ & $4.3^{\mathrm{b}, \mathrm{c}}$ & $5.2^{\mathrm{a}, \mathrm{b}}$ & $4.8^{\mathrm{b}, \mathrm{c}}$ & $4^{\mathrm{b}, \mathrm{c}}$ & $4.2^{\mathrm{b}, \mathrm{c}}$ & $3^{c}$ & $3.7^{\mathrm{b}, \mathrm{c}}$ \\
\hline Butter flavor & 1.9 & 12.4 & 3.3 & 0.8 & $5.6^{\mathrm{a}}$ & $3.4^{\mathrm{b}, \mathrm{c}}$ & $4.5^{\mathrm{a}, \mathrm{b}}$ & $3.8^{\mathrm{b}}$ & $2.3^{\mathrm{c}, \mathrm{d}}$ & $2.1^{\mathrm{c}, \mathrm{d}}$ & $1.6^{\mathrm{d}}$ & $1.5^{\mathrm{d}}$ \\
\hline \multicolumn{13}{|l|}{ Aftertaste } \\
\hline Acid aftertaste & 2.3 & 7.9 & 9.5 & 0.8 & $3.8^{\mathrm{b}}$ & $4.4^{\mathrm{b}}$ & $4.1^{\mathrm{b}}$ & $4.9^{\mathrm{b}}$ & $5.3^{\mathrm{b}}$ & $4.8^{\mathrm{b}}$ & $8^{\mathrm{a}}$ & $4.5^{\mathrm{b}}$ \\
\hline Bitter aftertaste & 1.3 & 1.7 & 5.0 & 0.8 & $3.5^{\mathrm{a}}$ & $2.7^{\mathrm{a}}$ & $2.8^{\mathrm{a}}$ & $3.8^{\mathrm{a}}$ & $4.7^{\mathrm{a}}$ & $2.6^{\mathrm{a}}$ & $3.1^{\mathrm{a}}$ & $3.8^{\mathrm{a}}$ \\
\hline Fermentation aftertaste & 1.6 & 0.9 & 8.6 & 0.7 & $4.9^{\mathrm{a}}$ & $3.7^{\mathrm{a}}$ & $4^{\mathrm{a}}$ & $3.6^{\mathrm{a}}$ & $3.5^{\mathrm{a}}$ & $3.6^{\mathrm{a}}$ & $3.8^{\mathrm{a}}$ & $3.8^{\mathrm{a}}$ \\
\hline Mouth coating & 2.6 & 11.2 & 8.3 & 1.0 & $5^{\mathrm{a}}$ & $5.3^{\mathrm{a}}$ & $4.1^{\mathrm{a}}$ & $3^{\mathrm{b}}$ & $4.2^{\mathrm{a}}$ & $2.5^{\mathrm{b}}$ & $2.3^{\mathrm{b}}$ & $1.7^{\mathrm{b}}$ \\
\hline Astringent & 2.5 & 2.4 & 12.4 & 1.1 & $3.2^{\mathrm{b}}$ & $3.2^{\mathrm{b}}$ & $3.4^{\mathrm{b}}$ & $3.4^{\mathrm{b}}$ & $3.6^{\mathrm{b}}$ & $3^{\mathrm{b}}$ & $5.2^{\mathrm{a}}$ & $3.6^{\mathrm{b}}$ \\
\hline Fat aftertaste & 1.8 & 9.9 & 2.1 & 1.0 & $4.2^{\mathrm{a}}$ & $3.4^{\mathrm{a}}$ & $3^{\mathrm{a}}$ & $2.9^{\mathrm{a}}$ & $1.4^{\mathrm{b}}$ & $1.3^{\mathrm{b}}$ & $1.2^{\mathrm{b}}$ & $1.1^{\mathrm{b}}$ \\
\hline
\end{tabular}

${ }^{\mathrm{a}-\mathrm{d}}$ Means with different letters differ significantly at $P<0.05$ (Student-Neuman-Keuls test).

${ }^{1}$ Bold and italic characters correspond to significant values $(P<0.05)$. $\mathrm{F}_{\text {model }}$ corresponds to the Fisher values of the ANOVA model; $\mathrm{F}_{\text {product }}$ corresponds to the Fisher values for the product effect; $\mathrm{F}_{\text {subject }}$ corresponds to the Fisher values for the subject effect; and $\mathrm{F}_{\text {prod } \times \text { subj }}$ corresponds to the Fisher values for the interaction product $\times$ subject. For each Fisher value, degrees of freedom associated are given in index. 


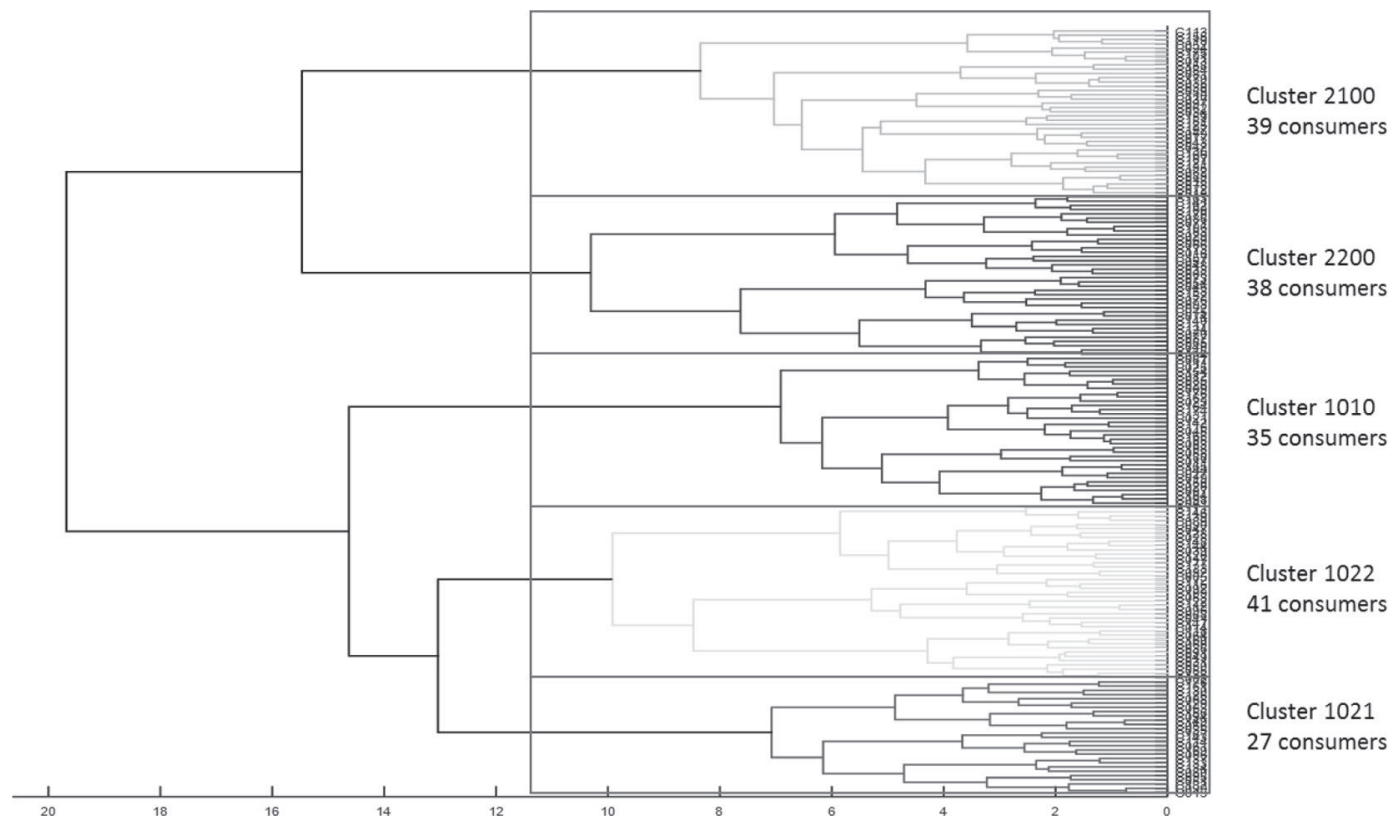

Figure 2. Results of hierarchical cluster analysis on normalized data.

using ANOVA $(P<0.05)$. The HCA performed on the normalized consumer data enabled identification of 5 clusters of consumers, each containing from 27 to 41 consumers (Figure 2).

A 2-way ANOVA with group, product, and group $\times$ product effects was computed on hedonic scores to check for differences in liking scores between yogurts and between groups. The group $\times$ product interaction was highly significant $(P<0.05)$ : some products had higher or lower mean scores than others. In other words, different groups had differing opinions on the products.

Results of ANOVA for each cluster with consumer, product, and order of presentation effect showed that the product effect was significant $(P<0.05)$ for each cluster. Results of the Newman-Keuls comparison showed that each cluster of consumers displayed a different behavior (Figure 3). In 4 clusters, the product set was clearly divided into 2 parts: yogurts with a score lower than the average, and yogurts with a score higher than the average. In the last cluster (1022), segmentation of the product set was not evident.

Regarding the 3 variables used to constitute the product set (set/stirred, yogurt/Bifidus, standard fat $/ 0 \%$ fat), it was not simple to explain the preferences of the 5 clusters. Cluster 1021 rejected only the stirred yogurts, and cluster 2200 rejected Bifidus content with standard fat level.

Preference Mapping. Preference mapping usually uses the first 2 axes. Although this is simple, there are some drawbacks. In particular, sensory descriptors with a higher weight (those that are highly correlated) may not be those that are relevant to understanding consumer preferences. Indeed, the relevant descriptors may be on axes other than the first 2. For example, astringent, acid, and acid aftertaste attributes contributed markedly to axis 2-the products were very different for these variables. However, these variables could also be irrelevant to understanding preferences, because they were not the most relevant variables for the consumers (Table 4).

For this reason, we computed preference maps for all pairs of axes (Figure 4). According to the eigenvalue, 4 axes were selected. To compare the results, we determined the pair that led to the highest correlation coefficient (Equation 2). This methodology was used for each cluster of customers (Table 5).

For 4 of the 5 clusters, the 3-4 plane was retained. For cluster 1022, the 1-3 plane was retained. For clusters 1021 and 2200, an area with high preferences in the diagonal of the plane was observed. The 2 diagonals were orthogonal among them. The zones of preferences and rejections in clusters 1010 and 2100 were opposed.

We defined the optimal product on the preference mapping as the barycenter (centroid) of $\{(\mathrm{A}, \mathrm{a})(\mathrm{B}, \mathrm{b})$ $(\mathrm{C}, \mathrm{c})\}$ with $\mathrm{a}+\mathrm{b}+\mathrm{c} \neq 0$, where $\mathrm{A}, \mathrm{B}$, and $\mathrm{C}$ are the 3 closest products of the optimal product on the PCA map. Then, we applied the linear combination with values of $\mathrm{a}, \mathrm{b}$, and $\mathrm{c}$ (coefficients of the barycenter) to the sensory scores. Using this centroid point method, several optimum products and their corresponding sen- 
sory characteristics were identified for each cluster. For group 2200, the gray "+" represents all the optimum products (Figure 5).

Because there were more than 2 optimum products per group, it was possible to compute one-way ANOVA with the group effect on all the sensory descriptors. This enabled ranking of the sensory descriptors according to differences in expected values for optimum products (Table 6). The greater differences concerned the attributes brilliance, acid, color, butter flavor, milk flavor, fat aftertaste, and quantity of whey. To represent one optimum product for each group, we selected the most central optimum product on the sensory map that was the closest to the centroid (Figure 6).

Finally, the clusters were characterized according to the results of the cognitive restraint questionnaire. We used a standard method to characterize groups with illustrative qualitative variables. The main idea was
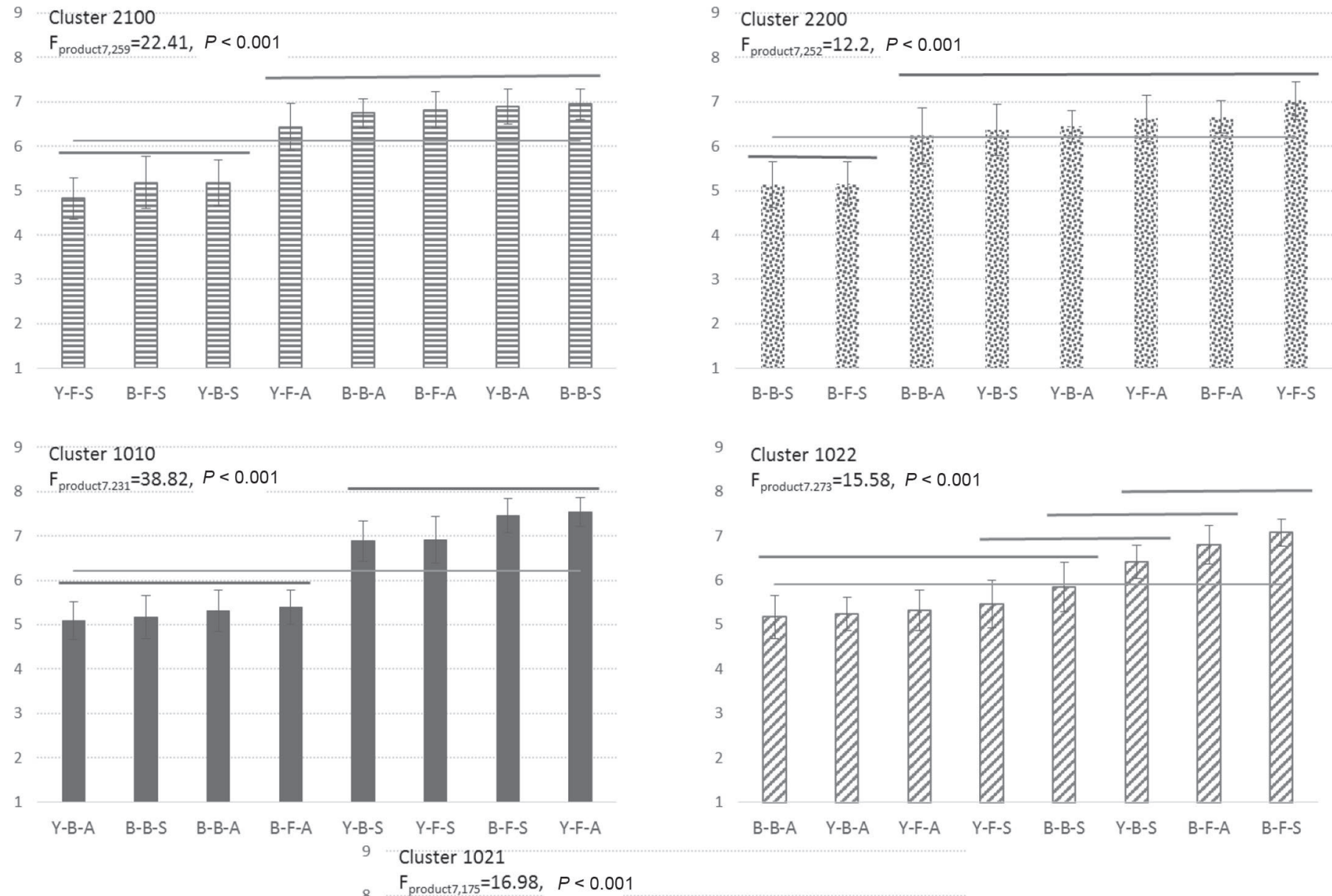

$8 \quad F_{\text {product } 7,175}=16.98, P<0.001$

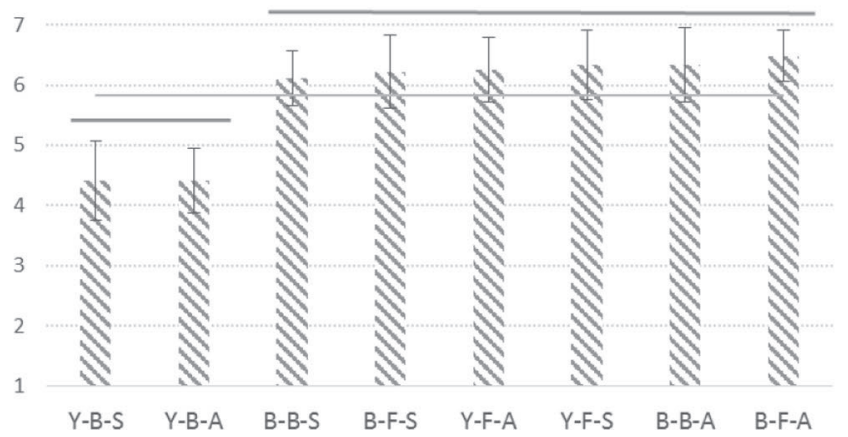

Figure 3. Average score of preferences for each cluster of consumers. Yogurt designations are given in Table 1. 
Table 4. Percentage contribution of each descriptor to each axis of principal components analysis on sensory scores

\begin{tabular}{|c|c|c|c|c|c|c|c|}
\hline \multirow[b]{2}{*}{ Descriptor } & \multicolumn{7}{|c|}{ Principal component axis } \\
\hline & $\mathrm{F} 1$ & $\mathrm{~F} 2$ & F3 & $\mathrm{F} 4$ & F5 & F6 & F7 \\
\hline Astringent & 3 & 21 & 2 & 1 & 5 & 4 & 32 \\
\hline Acid & 3 & 19 & 3 & 3 & 13 & 1 & 3 \\
\hline Acid aftertaste & 3 & 19 & 0 & 3 & 1 & 15 & 0 \\
\hline Brilliance & 6 & 0 & 10 & 0 & 21 & 0 & 5 \\
\hline Butter flavor & 4 & 2 & 15 & 3 & 2 & 1 & 0 \\
\hline Color & 7 & 1 & 6 & 2 & 4 & 14 & 11 \\
\hline Crisp with spoon & 8 & 1 & 1 & 0 & 1 & 4 & 0 \\
\hline Fat aftertaste & 5 & 2 & 15 & 1 & 1 & 4 & 3 \\
\hline Flowing texture & 8 & 1 & 1 & 1 & 0 & 2 & 0 \\
\hline Granularity in mouth & 8 & 2 & 0 & 0 & 6 & 4 & 6 \\
\hline Granularity in the spoon & 8 & 1 & 1 & 0 & 0 & 1 & 1 \\
\hline Granularity on the surface area & 6 & 11 & 1 & 0 & 0 & 12 & 8 \\
\hline Milk flavor & 4 & 4 & 10 & 9 & 4 & 27 & 9 \\
\hline Mouth coating & 8 & 0 & 1 & 5 & 1 & 3 & 0 \\
\hline Quantity of whey & 0 & 4 & 29 & 4 & 35 & 0 & 6 \\
\hline Sticking in mouth & 3 & 3 & 3 & 37 & 3 & 1 & 0 \\
\hline Sticking with spoon & 8 & 2 & 0 & 0 & 3 & 3 & 14 \\
\hline Sweet & 8 & 0 & 1 & 0 & 0 & 0 & 0 \\
\hline Thickness & 2 & 8 & 3 & 31 & 0 & 4 & 1 \\
\hline Sum & 100 & 100 & 100 & 100 & 100 & 100 & 100 \\
\hline
\end{tabular}

to test whether the differences in having a particular modality of the variable, between the proportion in a particular group and the proportion in the whole population, were significant (Nakache and Confais, 2005). Cluster 1022 was characterized by consumers who were watching their weight and controlling their dietary intake. Cluster 1010 was characterized by single people who were not watching their weight and eating all types of foods. No patterns could be clearly identified in the 3 other groups.

\section{DISCUSSION}

The approach described here enabled us to study the preferences of consumers of plain yogurts and the relationship between these preferences and the sensory properties of the yogurts. The large number of consumers examined permitted investigation of different preference profiles and identification of the ideal sensory profile in each consumer cluster.

Eight commercial yogurts were used. Accordingly, thresholds for each modality (texture, health component, and fat content) were not controlled. The product space comprised 8 products, which allowed use of the quadratic model for preference mapping. This enabled identification of the optimal products for the different consumer clusters thus determined. However, the results showed that obtaining a product that gained consensus among all consumers was not a viable solution: consumers liked different products. The cluster-based approach was nevertheless able to identify 5 ideal prod- ucts associated with particular sensory characteristics. For example, consumers of cluster 1021 preferred yogurts with a strong intensity of thickness, with graininess, but with a less flowing texture, less sticky, whey presence, and color, in contrast to consumers of cluster 2100, whose optimal product was less thick, less grainy in mouth, with a strong intensity in flowing texture, thickness with spoon, with a high quantity of whey and color.

The clusters were also characterized according to the results of the cognitive restraint questionnaire, and these results showed that patterns were only identified regarding 2 clusters. However, the clusters identified during the present study could be constituted using a limited number of consumers (i.e., fewer than 50). The results were consequently balanced. In 4 of the 5 clusters, the preferences were clearly segmented. In contrast, the preferences in cluster 1022 displayed only small variations between products. This may have been due to the heterogeneity of consumer preferences. Indeed, the results of hierarchical analyses showed that this cluster was the least homogeneous. One solution would have been to divide this cluster, but that would have led to fewer consumers in the clusters. This observation was consistent with the results of preference mapping, which revealed a weak prediction of preferences in this cluster (1022). Apart from cluster 1022, and according to correlation coefficients, the predictions of preferences in the 4 other clusters were good. It is interesting to note that plane 1-2 was never selected. This finding was consistent with those of Arditti (1997) and Daillant- 
Spinnler et al. (1996), who noted that some consumer preferences fitted better with planes composed using axes 2 or 3 . This could be explained by the fact that a variable or a set of variables could be highly correlated with the first plane, because the products are very different for these variables or because theses variables are highly correlated but without having any effect on consumers' preferences.
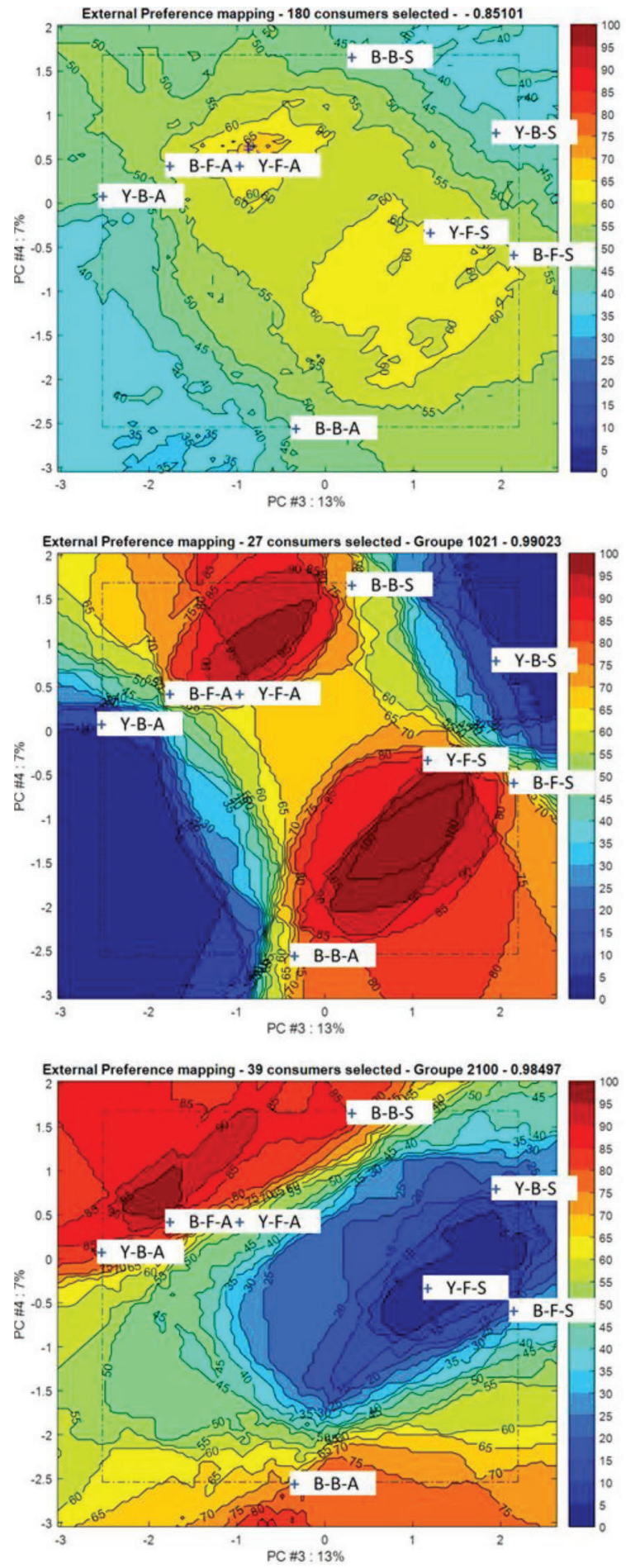
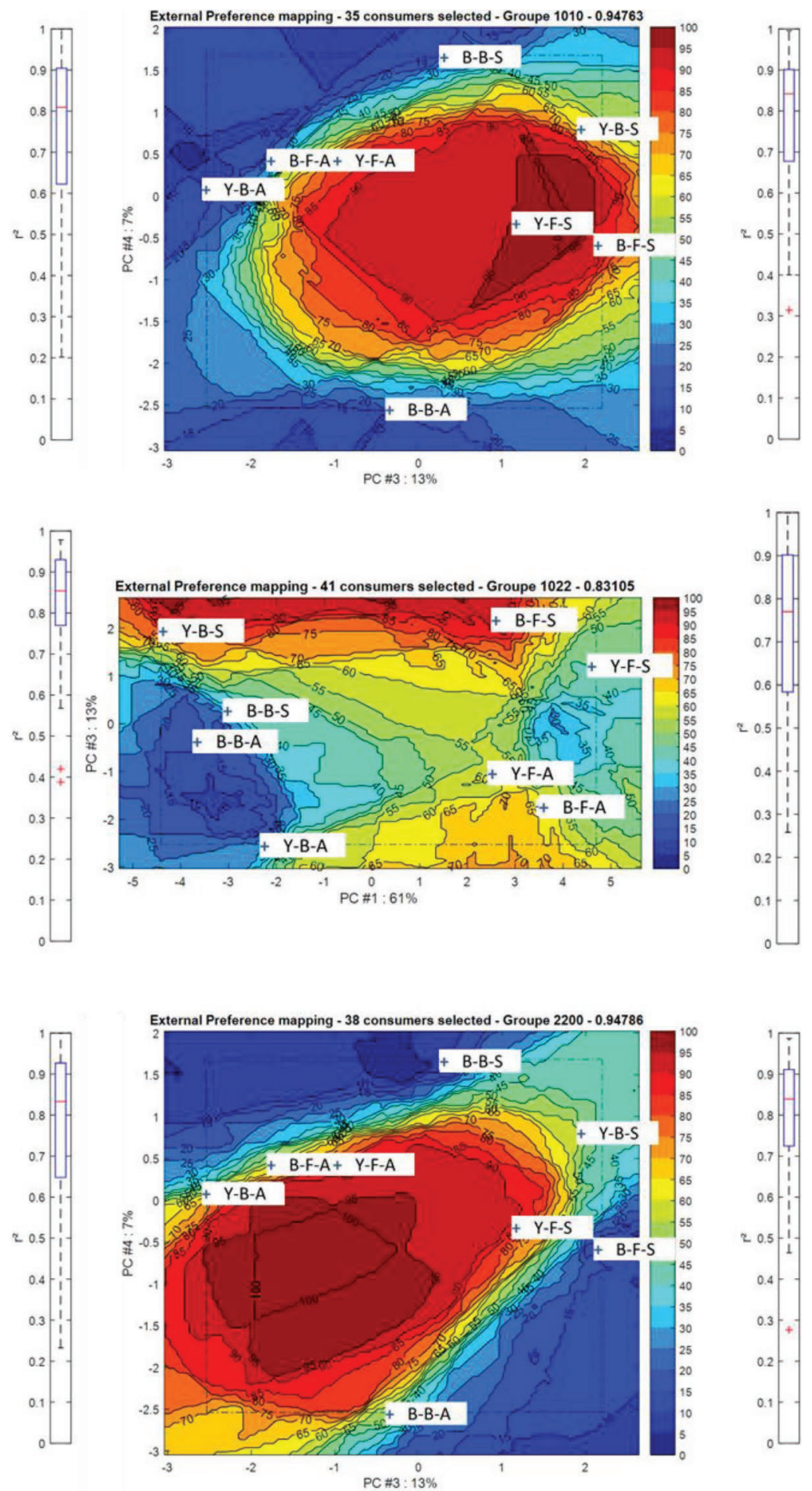

Figure 4. Results of external preference mapping for all consumers and each cluster. Yogurt designations are given in Table 1. PC $=$ principal component. Color version available online. 
Table 5. Correlation coefficients for each combination of axes and each cluster of consumer preferences ${ }^{1}$

\begin{tabular}{lccccc}
\hline & \multicolumn{4}{c}{ Axis combination } \\
\cline { 2 - 6 } Cluster & $1-2(76 \%)$ & $1-3(74 \%)$ & $1-4(65 \%)$ & $2-3(28 \%)$ & $2-4(22 \%)$ \\
\hline 1010 (35 consumers) & 0.93 & 0.79 & 0.59 & 0.90 & 0.49 \\
1021 (27 consumers) & 0.84 & 0.88 & 0.96 & 0.90 & 0.98 \\
1022 (41 consumers) & 0.72 & $\mathbf{0 . 8 3}$ & 0.33 & 0.82 & 0.71 \\
2100 (39 consumers) & 0.74 & 0.95 & 0.92 & 0.95 & 0.95 \\
2200 (38 consumers) & 0.91 & 0.89 & 0.93 & 0.81 & 0.94 \\
\hline
\end{tabular}

${ }^{1}$ Bold characters correspond to the best combination of axes for each cluster of consumers.

Table 6. One-way ANOVA group effect on sensory descriptors

\begin{tabular}{lcc}
\hline Attribute & $\mathrm{F}$ & $\mathrm{Pr}>\mathrm{F}$ \\
\hline Brilliance & 392,970 & $<0.0001$ \\
Acid & 271,348 & $<0.0001$ \\
Color & 238,164 & $<0.0001$ \\
Butter flavor & 180,819 & $<0.0001$ \\
Milk flavor & 179,912 & $<0.0001$ \\
Fat aftertaste & 149,689 & $<0.0001$ \\
Quantity of whey & 147,908 & $<0.0001$ \\
Astringent & 99,540 & $<0.0001$ \\
Acid aftertaste & 84,118 & $<0.0001$ \\
Thickness & 62,468 & $<0.0001$ \\
Sweet & 43,204 & $<0.0001$ \\
Sticking with spoon & 36,306 & $<0.0001$ \\
Granularity in mouth & 32,219 & $<0.0001$ \\
Sticking in mouth & 29,518 & $<0.0001$ \\
Mouth coating & 27,173 & $<0.0001$ \\
Granularity in the spoon & 26,836 & $<0.0001$ \\
Crisp with spoon & 24,441 & $<0.0001$ \\
Granularity on the surface area & 22,412 & $<0.0001$ \\
Flowing texture & 21,904 & $<0.0001$ \\
\hline
\end{tabular}

Significant differences in preferences were observed between specific groups of consumers. Surprisingly, no consensus regarding preference was reached among consumer clusters with respect to the fat content of yogurts. Consumers in cluster 1022 tended to reject the low-fat yogurts, unlike those in cluster 2100, who tended to reject the standard fat yogurts. Several factors could explain this difference, including the multimodal role of fat, which can affect not only taste and flavor but also numerous sensory properties (Brauss et al., 1999; Le Calvé et al., 2015). A preference for higher-fat products may also depend on the fat threshold of each individual.

The results of preference mapping showed that the area of high preference did not always contain an actual product, thus highlighting the usefulness of this method in product optimization. To validate these results, it would be interesting to develop the optimal products thus identified. Our findings also confirm the establishment of relationships between sensory properties, the manufacturing process, and the formulation of recipes.

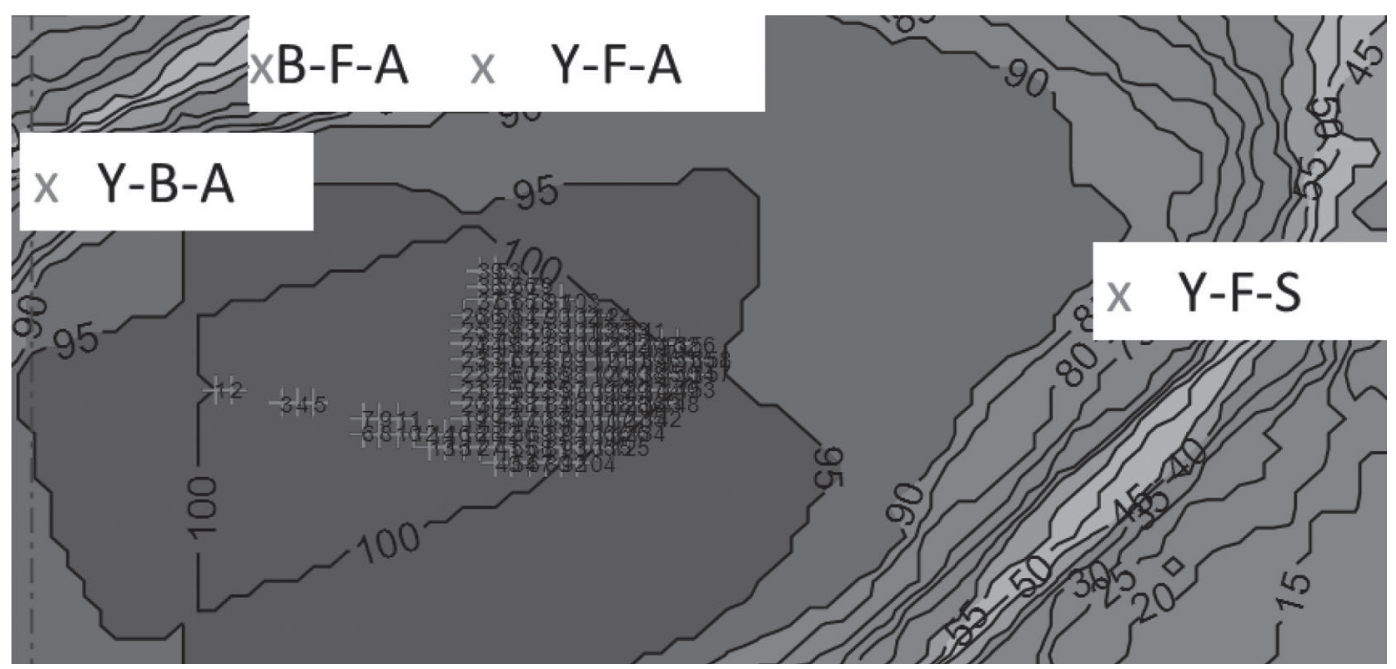

Figure 5. Ideal products for group 2200. Yogurt designations are given in Table 1. 


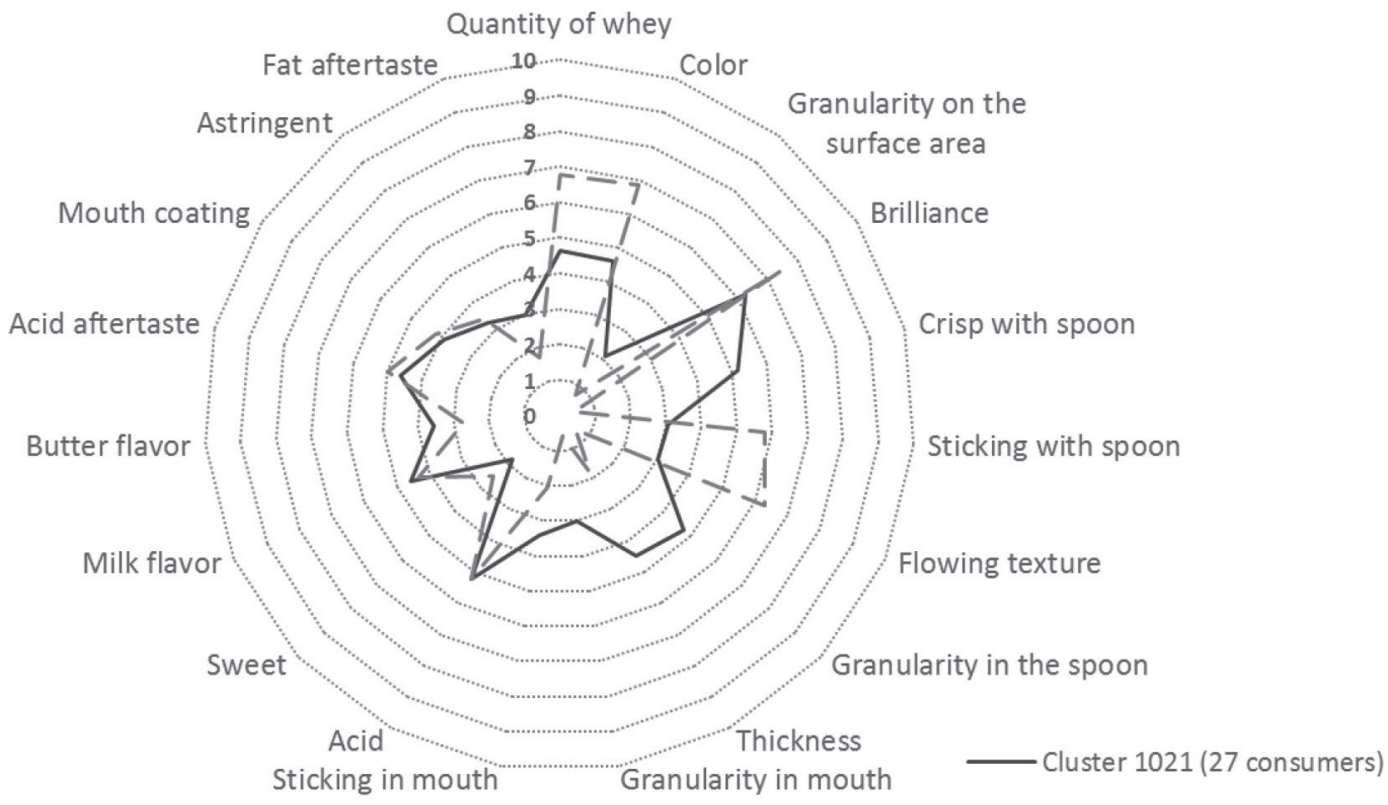

Figure 6. Ideal yogurt profiles for clusters 1021 and 2100.

\section{CONCLUSIONS}

In this study, different areas of high preferences for various yogurt sensory properties were identified and were specific to clusters of consumers. Large differences in thickness, granularity, flowing texture, sticky, whey presence, and color perception were observed between the optimal products identified for different consumer clusters.

\section{ACKNOWLEDGMENTS}

This work received support from the French National Research Agency under the "Investissements d'Avenir" program (reference No. ANR-11-IDEX-0003-02). We thank Noémie Lucet (AgroParisTech, France) for her contribution to this study.

\section{REFERENCES}

Arditti, S. 1997. Preference mapping: A case study. Food Qual. Prefer. 8:323-327.

Barnes, D. L., S. J. Harper, F. W. Bodyfelt, and M. R. McDaniel 1991. Correlation of descriptive and consumer panel flavor ratings for commercial prestirred strawberry and lemon yogurts. J. Dairy Sci. 74:2089-2099.

Blumenthal, D., and S. Bouillot. 2010. CARTOPTI: A tool for automotive seat conception using regression models and customers studies. Pages 2188-2197 in Proc. Int. Conf. Kansei Engineering and Emotion Research (Keer), Paris, France. Anais, Paris, France.

Bonany, J., C. Brugger, A. Buehler, J. Carbó, S. Codarin, F. Donati, G. Echeverria, S. Egger, W. Guerra, C. Hilaire, I. Höller, I. Iglesias, K. Jesionkowska, D. Konopacka, D. Kruczyńska, A. Martinelli, C. Petiot, S. Sansavini, R. Stehr, and F. Schoorl. 2014
Preference mapping of apple varieties in Europe. Food Qual. Prefer. 32:317-329.

Brauss, M. S., R. S. T. Linforth, I. Cayeux, B. Harvey, and A. J. Taylor. 1999. Altering the fat content affects flavor release in a model yogurt system. J. Agric. Food Chem. 47:2055-2059.

Chandan, R. C., and K. R. O'Rell. 2006. Principles of yogurt processing. Pages 195-197 in Manufacturing Yogurt and Fermented Milks. Blackwell Publishing, Oxford, UK.

Chang, J. J., and J. D. Carroll. 1972. How to use PREFMAP and PREFMAP-2 \{Programs which relate preference data to multidimensional scaling solutions\}. Bell Telephone Labs, Murray Hill, NJ.

CNIEL. 2012. Activity Report. The French Directorate General for Food. Accessed Feb. 17, 2016. www.agriculture.gouv.fr.

Daillant-Spinnler, B., H. J. H. MacFie, P. K. Beyts, and D. Hedderley. 1996. Relationships between perceived sensory properties and major preference directions of 12 varieties of apples from the Southern Hemisphere. Food Qual. Prefer. 7:113-126.

Danzart, M., J.-M. Sieffermann, and J. Delarue. 2004. New developments in preference mapping techniques: Finding out a consumer optimal product, its sensory profile and the key sensory attributes. In 6th Sensometric Meeting, Davis, CA

Desai, N. T., L. Shepard, and M. A. Drake. 2013. Sensory properties and drivers of liking for Greek yogurts. J. Dairy Sci. 96:7454-7466.

Dooley, L., Y. S. Lee, and J. F. Meullenet. 2010. The application of check-all-that-apply (CATA) consumer profiling to preference mapping of vanilla ice cream and its comparison to classical external preference mapping. Food Qual. Prefer. 21:394-401.

Elmore, J. R., H. Heymann, J. Johnson, and J. E. Hewett. 1999. Preference mapping: Relating acceptance of "creaminess" to a descriptive sensory map of a semi-solid. Food Qual. Prefer. 10:465-475.

Faber, N. K. M., J. Mojet, and A. A. Poelman. 2003. Simple improvement of consumer fit in external preference mapping. Food Qual. Prefer. 14:455-461.

Gaze, L. V., B. R. Oliveira, L. L. Ferrao, D. Granato, R. N. Cavalcanti, C. C. Júnior, A. G. Cruz, and M. Q. Freitas. 2015. Preference mapping of dulce de leche commercialized in Brazilian markets. J. Dairy Sci. 98:1443-1454.

Guinard, J. X., B. Uotani, and P. Schlich. 2001. Internal and external mapping of preferences for commercial lager beers: Comparison 
of hedonic ratings by consumers blind versus with knowledge of brand and price. Food Qual. Prefer. 12:243-255.

Harper, S. J., D. L. Barnes, F. W. Bodyfelt, and M. R. McDaniel. 1991. Sensory ratings of commercial plain yoghurts by consumer and descriptive panels. J. Dairy Sci. 74:2927-2935.

Helgesen, H., R. Solheim, and T. Næs. 1997. Consumer preference mapping of dry fermented lamb sausages. Food Qual. Prefer. 8:97109.

Hough, G., N. Bratchell, and I. Wakeling. 1992. Consumer preference of dulce de leche among students in the United Kingdom. J. Sens. Stud. 7:119-132.

Hough, G., and R. Sánchez. 1998. Descriptive analysis and external preference mapping of powdered chocolate milk. Food Qual. Prefer. 9:197-204

Kaaki, D., O. K. Baghdadi, N. E. Najm, and A. Olabi. 2012. Preference mapping of commercial Labneh (strained yogurt) products in the Lebanese market. J. Dairy Sci. 95:521-532.

Le Calvé, B., C. Saint-Leger, R. Babas, J.-L. Gelin, A. Parker, P. Erni, and I. Cayeux. 2015. Fat perception: How sensitive are we? J. Texture Stud. 46:200-211.

Munoz, A. M., and I. V. E. Chambers. 1993. Relating sensory measurements to consumer acceptance of meat products. Food Technol. 47:128-131.
Nakache, J. P., and J. Confais. 2005. Approche Pragmatique de la Classification. Editions Techhnip, Paris, France.

Pohjanheimo, T., and M. Sandell. 2009. Explaining the liking for drinking yoghurt: The role of sensory quality, food choice motives, health concern and product information. Int. Dairy J. 19:459-466.

Schlich, P. 1995. Preference mapping: Relating consumer preferences to sensory or instrumental measurements. Colloques de l'TNRA, France. Agris, vol. 75, Dijon, France.

Sodini, I., F. Remeuf, S. Haddad, and G. Corrieu. 2004. The relative effect of milk base, starter, and process on yogurt texture: A review. Crit. Rev. Food Sci. Nutr. 44:113-137.

Stunkard, A. J., and S. Messick. 1985. The three-factor eating questionnaire to measure dietary restraint, disinhibition and hunger. J. Psychosom. Res. 29:71-83.

Wold, S., A. Ruhe, H. Wold, and W. J. Dunn III. 1984. The collinearity problem in linear regression. The partial least squares (PLS) approach to generalized inverses. SIAM J. Sci. Statist. Comput. $5: 735-743$. 